\title{
Question and Answer Sessions with Dr. Shin-Ichi Nishikawa
}

\section{Osaka}

\section{Chairman: Dr. Akira Negi}

(Kobe Univ.)

Dr. Negi: Thank you Dr. Nishikawa for the excellent lecture. You clearly explained how the retina is ideal for the study of vascular remodeling. I was greatly impressed by the fact that angiopoietin restores the vasculature of the retina without pericytes. You also spoke about the use of cadherins for visualizing the movement of cellular walls in the ES cell culture. I thought it was extraordinary to be able to observe such movement in real time. You mentioned Dr. Uemura. Is Dr. Uemura here?

Dr. Nishikawa: Yes, he is.

Dr. Negi: Could you stand up, Dr. Uemura?

Dr. Nishikawa: Most of the work was his achievement.

Dr. Negi: I am very glad to see you. On this occasion, would you take some questions from the audience?

Dr. Nishikawa: It might be best to ask him to answer questions later at the reception party.

Dr. Negi: I agree. Now, I am excited to hear that angiopoietin restores the vascular architecture of the retina without pericytes.

Dr. Nishikawa: It was indeed a great surprise. Of course, the vasculature still has abnormalities. The process does not proceed beyond a certain point in accumulating abnormalities, and it is impossible to obtain complete blood vessels in this way. So, this work clearly demonstrates that blood vessels do not function without remodeling. Because Dr. Uemura is an ophthalmologist, he is not satisfied with what he has done so far. He now wants to produce microaneurysms. At this stage, his experimental model may be useful for screening drug candidates, but it is not an effective tool for studying important pathologies. So, both he and we are eagerly tackling new problems. We have no secrets in this study. You may ask whatever you want, and he will be willing to answer any questions.

Dr. Negi: Are there any questions you want to ask here? If not, I want to close the $\mathrm{Q} \&$ A session for this very exciting lecture. As the doctors will take questions later at the reception party, please take the opportunity and ask your questions there.

Dr. Nishikawa: Thank you very much.

Dr. Negi: Thank you, Dr. Nishikawa.

\section{Tokyo}

\section{Chairman: Dr. Makoto Tamai}

(Tohoku Univ.)

Dr. Tamai: Thank you for the splendid lecture. Now I invite comments and questions from the audience. Please state your name and affiliation first.

Dr. Noda: I am Dr. Noda from the Department of Ophthalmology, Keio University. Thank you for the presentation of the results of very valuable experiments. I have two questions. One is related to the slide entitled 'The molecular and cellular cascade of retinal angiogenesis'. The slide contained a statement that PDGF-alpha stimulates astrocytes. I am studying Müller cells in relation to VEGF. Do you have any experimental data concerning the effects of PDGF-alpha on Müller cells?

\begin{tabular}{ll}
\hline KARGER & $\begin{array}{l}\text { () 2003 S. Karger AG, Basel } \\
0030-3755 / 03 / 2177-0043 \$ 19.50 / 0\end{array}$ \\
$\begin{array}{l}\text { Fax +4161306 12 34 } \\
\begin{array}{l}\text { E-Mail karger@karger.ch } \\
\text { www.karger.com }\end{array}\end{array}$ & $\begin{array}{l}\text { Accessible online at: } \\
\text { www.karger.com/oph }\end{array}$
\end{tabular}


Dr. Nishikawa: I have no data beyond what is written in the paper that was published in Neuron in 1996. I will send you a reprint of this paper. Our study aim was not a detailed analysis. We just monitored the network that was stained with GFAP, and demonstrated suppression of the GFAP-positive network. Previously, Bill Richardson's group studied the involvement of PDGF in the differentiation of neural stem cells into astrocytes. Because he is an expert in this field, it is possible that he might have made some observations pertaining to Müller cells. In our study, we investigated the whole category of cells grossly represented as GFAP-positive cells. We have not focused on this particular problem.

Dr. Noda: Thank you. Let me now ask the other question.

Dr. Nishikawa: Please go ahead.

Dr. Noda: You said that PDGF-beta induces pericytes in the recruitment of pericytes. Is this related to the differentiation of mesenchymal cells or cell migration?

Dr. Nishikawa: Clearly, in the case of the retina, it is related to the overall process of proliferation and migration of cells that have existed in blood vessels from the beginning. We also studied the process in early embryogenesis, and published a paper in Nature in 2000. In this case, progenitors produce both pericytes and endothelial cells. These are produced in conjunction. The vasculature of the retina seems to develop via a different process, in which proliferation of existing pericytes takes place in a PDGF-beta-dependent and receptor-beta-dependent manner, with recruitment also taking place simultaneously.

Dr. Noda: I see. Thank you very much.

Dr. Tamai: I wonder about several issues raised in your lecture. The retina in the early stage of development lacks blood vessels. Then, two layers of capillary vessels form, one inside and the other outside. The Müller cell processes direct endothelial cells, which direct formation of the complete network, as you said. Is it reasonable to consider a primary network of capillaries to form in the first place, and to then be remodeled in the same manner as the formation of fingers through apoptosis of the tissue between the fingers?
Dr. Nishikawa: An interesting fact is that the blood vessels in the vitreous body disappear almost at once. For example, Dr. Uemura is now conducting gene knock-out analyses of orphan receptors. Such experiments result in a large variety of abnormal features, such as aberrant flow between the capillary network and the retinal network. In addition, the blood vessels in the vitreous body persist. On the other hand, remodeling does not occur in the retinal network. He is now attempting to determine why these various changes are caused by one molecular species. It seems that several different systems work in a coordinated manner, and things do not progress normally if something remains in either of the systems. The only method we can use at present is to knock out one molecule, and this situation is rather frustrating. If we want to be able to answer your question, we must develop new methods, such as cell transplantation or an experimental tool for producing a structure in the places where it is missing. I think it is impossible for the time being to answer such complicated questions. One possible direction is to utilize what we already have toward the goal of producing something like a microaneurysm. At present, we can perform gene knock-out analyses, but I have no idea how to approach the problems you suggested.

Dr. Tamai: Thank you. Are there any other questions? I think it is very interesting, marvelous really, that fetuses grow normally even when we knock out important genes such as this one.

Dr. Nishikawa: It is indeed interesting. Orphan receptors are defined based on the associated abnormality of the retinal neural network. However, if ophthalmologists specializing in blood vessels observed such abnormalities, they would have different opinions. Many of the gene knock-out analyses that have resulted in an ocular abnormality may be based on more or less loosely defined concepts. Those who are intrigued by this field may find many interesting themes in this area of study.

Dr. Tamai: I agree. It looks like a treasure trove of research themes. No more questions? Thank you very much.

Dr. Nishikawa: Thank you very much. 